\title{
Prevalence Of Nicotine Use and Dependence in Depression
}

\author{
Dhungel $B^{1}$, Chapagai $M^{2}$, Pant $S^{3}$, Tulachan $P^{2}$, Dhungana $S^{3}$ \\ 1. Psychiatrist, Mental Hospital, Lagankhel, Lalitpur, Nepal 2 Associate Professor, Department of \\ Psychiatry \& Mental Health, Maharajgunj Medical campus, Kathmandu, Nepal 3. Assistant Professor, \\ Department of Psychiatry \& Mental Health, Maharajgunj Medical campus, Kathmandu, Nepal
}

E-mail *Corresponding author : binitaenator@gmail.com

\section{Abstract}

Introduction: Prevalence of tobacco use is universal and individuals suffering from mental disorders come with no exceptions. There is paucity of study looking into prevalence of tobacco use and nicotine dependence in patients with depression in low income countries like Nepal. Thus this study aimed at determining the prevalence of tobacco consumption, nicotine dependence and motivation to quit in patients with major depressive disorders.

Material And Method: A descriptive cross-sectional study was done among inpatient and out patients with diagnosis of depression at department of psychiatry and mental health, Tribhuvan University Teaching Hospital (TUTH). Data were collected using semi-structured Porforma and WHO STEPS Instrument for Nicotine Use. Fagerström Test for Nicotine Dependence, Modified Fagerström - Smokeless Tobacco, and Assessment of Motivation: Readiness to Quit Ladder was applied for nicotine users. Data were tabulated and analyzed using Statistical Package for Social Sciences version 20.0 (SPSS version 20.0).

Results: A total of 121 patients with diagnosis of depression were enrolled in the study. $37.2 \%(n=45)$ of patient used smoked tobacco only, 9.1\% $(n=13)$ used smokeless tobacco and $10.7 \%(n=11)$ used both smoked and smokeless tobacco. $92.3 \%$ of patients using smokeless forms of tobacco were nicotine dependent whereas this figure reaches to $81.8 \%$ in combined users. Median value of readiness to quit tobacco was 6 which indicates they often think about quitting but without any plans which was statistically significant $(p<0.05)$.

Conclusion: Prevalence of nicotine use and dependence was found high among people with depression. Use of standardized and translated screening tools can be used efficiently to evaluate the burden of nicotine use in standard clinical practice in low resource setting like Nepal.

Keywords: Depression, Nicotine, Nicotine dependence, Tobacco

\section{INTRODUCTION}

Tobacco use in various forms is identified as a major public health problem worldwide. $^{1}$ Globally, 942 million men and 175 million women ages 15 or older are current smokers. ${ }^{2}$ There is lack of systematic study evaluating the burden of tobacco use and nicotine dependence in Nepal. In a study done in 2013 by Nepal Health Research council, (with assistance from World Health Organization(WHO) following manual guidance of the STEPwise approach to surveillance (STEPS), the prevalence of tobacco use in Nepal including both smoke and smokeless is $30.8 \%$ of total population. There was higher prevalence in male (48.1\%) compared to female $(14.1 \%)$ among $15-69$ years' age group. ${ }^{3}$ The reports of survey in the United States, the United Kingdom, and Australia show that smoking is two to three times more prevalent among people with mental illness, when compared with the general population. ${ }^{4}$ Depression is twice more common in smokers than in nonsmokers, and four times as common in heavy smokers(Klungsoyr, 2006 \#181). More recently, an investigation of young adult smokers from the National Epidemiologic Study of Alcohol and Related Conditions (NESARC) demonstrated that daily smokers with depression were at increased risk for nicotine dependence after controlling for level of smoking and also when examining rates of nicotine dependence across the continuum of 
daily smoking behaviors ${ }^{5}$. That is, individuals with a lifetime diagnosis of depression showed higher rates of nicotine dependence at each level of daily smoking, ranging from 1 to 5 cigarettes per day to well over a pack per day, compared to individuals without a history of depression. ${ }^{5}$

Also in comparison to the general population, people with serious mental illness have a 25 years lower life expectancy and this difference is largely due to tobacco use, obesity and poor engagement in medical care.6,7 So under diagnosis and under treatment of tobacco use disorder degrades the quality of life.

Individual suffering from depression are predisposed to use tobacco in his/her life. Such behavior may lead to development of nicotine dependence. Significant morbidity and mortality is associated with these behaviors. So assessment of nicotine dependence in each psychiatric patient is very important.

Despite of this understanding, there is paucity of study looking into prevalence of tobacco use and nicotine dependence in patients with major depressive disorders in low income countries like Nepal. This study aimed at determining the prevalence of tobacco consumption, nicotine dependence and motivation to quit in such patients.

\section{MATERIAL AND METHOD}

This was a cross sectional study conducted in Department of Psychiatry and Mental Health, Maharajgunj Medical Campus, Tribhuwan University Teaching Hospital (TUTH), Kathmandu, Nepal. Cases diagnosed as Depression according to International Classification of Disease - 10 (ICD-10) were enrolled in the study from inpatient and outpatient department. The total duration of study was one year.

The ethical approval was obtained from institutional research board of TUTH. The informed consent was obtained from the participants before commencement of the study. The inclusion criteria were i. age 18 to 59 years (age group frequently found with the habit of nicotine use) with ICD-10 diagnosis of Depression and ii. Patients giving informed consent. The exclusion criteria were i. Patient's refusing to participate in the study or not giving informed consent, ii. Another concurrent psychiatric diagnosis.
The sample size $(n=121)$ was calculated with standard formula with least sample size needed. Purposive sampling method was used.

The following instruments were used to acquire the data viz. Semistructured questionnaire, WHO STEPS instrument for nicotine use, Fagerstorm test for nicotine dependence (FTND), Modified Fagerstorm for smokeless tobacco, Assessment of Motivation: Readiness to Quit Ladder.

Self-designed semi structured questionnaire was devised to obtain the socio- demographic characteristics of the study population.

The STEPS Non communicable Disease Risk Factor Survey, part of the STEP wise approach to surveillance (STEPS) Adult Risk Factor Surveillance project by the World Health Organization $^{8}$, is a survey methodology to help countries begin to develop their own surveillance system to monitor and fight against non-communicable diseases. Step 1 of WHO STEPS instrument that addresses data on current use of tobacco was used. This tool in nepali translated version was provided by Nepal Health Research Council. ${ }^{8}$

Fagerström Test for nicotine dependence is standard instrument for assessing the intensity of physical addiction to nicotine and contains six items that evaluate the quantity of cigarette consumption, the compulsion to use, and dependence. The items are summed to yield a total score of $0-10$. The higher the total Fagerström score, the more intense is the patient's physical dependence on nicotine. ${ }^{9}$

Modified Fagerström- Smokeless Tobacco is a modified version of the FTND for assessment of smokeless tobacco users and scored similar to FTND. ${ }^{10}$

The criteria to categorize the score of the nicotine dependence was $\leq 4$ : low to moderate dependence and $\geq 5$ : moderate to high dependence, for both Fagerström and Modified Fagerström tests. Fagerström test was used to categorize dependence in case of combined users.

Assessment of Motivation: Readiness to Quit Ladder is a contemplation Ladder, which was designed as a continuous measure of readiness to quit smoking. It consists of 11-point likert scale. It is single-choice, visual analogue scale that illustrate a ladder whose higher steps 
characterize greater levels of readiness to change. ${ }^{11}$

Statistical Analysis

Data analysis was performed using SPSS version 20.0. Analyses included standard descriptive statistics. Normally distributed variables are expressed as mean $\pm \mathrm{SD}$, whereas non-normally distributed variables are presented as median and range. Unpaired t-test was used for comparison of means between groups. Chisquare test was used for comparison of proportions between variables and differences in the frequency of the nature of criteria. Correlation between variables was analyzed using Spearman's rank correlation coefficient. A p-value $<0.05$ was considered statistically significant.

\section{RESULT}

The study included 121 patients (mean age: 35.9 \pm 11.13 years, 74 males and 47 females) with the diagnosis of Major Depressive Disorder (mean duration of illness: $1.46 \pm 1.92$ years), out of which $26(21.5 \%)$ were enrolled from Inpatient Department and 95 (78.5\%) were enrolled from Outpatient Department.

Out of 121 patients, 69 (57.02\%) used one or more forms of tobacco. A total of 45 patients (37.2\%) used only smoked tobacco and $11(9.1 \%)$ used both forms of tobacco. Proportion of user of any forms of tobacco is higher in males than in females $(p=0.028)$. (Table 1$)$

Table 1: Frequency table showing prevalence of nicotine use according to gender

\begin{tabular}{|l|l|l|l|l|}
\hline SN & Variable & $\begin{array}{l}\text { Male } \\
(\mathrm{n}=74)\end{array}$ & $\begin{array}{l}\text { Female } \\
(\mathrm{n}=47)\end{array}$ & $\begin{array}{l}\mathrm{p} \text { - } \\
\text { value }\end{array}$ \\
\hline 1 & Smoker & 35 & 10 & \multirow{2}{*}{0.028} \\
\hline 2 & $\begin{array}{l}\text { Smokeless } \\
\text { Tobacco } \\
\text { only }\end{array}$ & 13 & 0 & \\
\hline 3 & $\begin{array}{l}\text { Combined } \\
\text { users }\end{array}$ & 8 & 3 & \\
\hline
\end{tabular}

In case of smokers $(n=45)$ more than half (55.5\%) had high dependence and 20/45 (45.5\%) had moderate dependence. In smokeless category $(n=13)$, nearly all $(92.3 \%)$ had high dependence. Almost all $(9 / 11=81.8 \%)$ among combined users were highly dependent on nicotine.
Table 2: Nicotine dependence category according to Fagerstrom or Modified Fragerstrom test

\begin{tabular}{|l|l|l|l|}
\hline Class & $\begin{array}{l}\text { Smoker } \\
\text { only } \\
(\mathrm{n}=45)\end{array}$ & $\begin{array}{l}\text { Smokeless } \\
\text { only } \\
(\mathrm{n}=13)\end{array}$ & $\begin{array}{l}\text { Combined } \\
\text { users }(\mathrm{n}=11)\end{array}$ \\
\hline $\begin{array}{l}\text { Low to } \\
\text { Moderate }\end{array}$ & 20 & 1 & 2 \\
\hline High & 25 & 12 & 9 \\
\hline
\end{tabular}

Table 3: Frequency distribution of scores obtained in Assessment of Motivation: Readiness to Quit Ladder

\begin{tabular}{|l|l|l|}
\hline Score & Frequency & Percentage \\
\hline 1 & 5 & 7.3 \\
\hline 3 & 5 & 7.3 \\
\hline 4 & 9 & 13.0 \\
\hline 5 & 29 & 42.0 \\
\hline 6 & 2 & 2.9 \\
\hline 7 & 4 & 5.8 \\
\hline 8 & 15 & 21.7 \\
\hline Total & 69 & 100 \\
\hline
\end{tabular}

Relatively small percentage of nicotine users $(21.7 \%)$ were strongly determined to quit the use of any forms of tobacco. The median score (also with highest frequency $(42.0 \%)$ ) on readiness to quit ladder was 5 which means the nicotine users often think of quitting but they do not have plans to quit.

There was a negative correlation between nicotine dependence and scores on readiness to quit ladder among current smoked tobacco users $(\mathrm{r}=-0.32, \mathrm{p}=0.03))$ and among smokeless tobacco users $(r=-0.11, p=0.7))$. This denotes strong association of continuing using smoked tobacco $(p=0.03)$ where in case of smokeless tobacco users, this association is not statistically significant $(p=0.7)$. In case of combined users, there is low association of quitting and dependence $(r=-0.19, p=0.6)$.

\section{DISCUSSION:}

The prevalence of nicotine use $(n=69,57.024 \%)$ and dependence $(n=46,38 \%)$ among tobacco user observed from our study was similar to the results shown in a study by Aggarwal $\mathrm{N}$ et al $(2018)^{12}$, in which out of 256 tobacco users, 146 $(57 \%)$ stated tobacco dependence while 110 $(43 \%)$ reported harmful use. Tobacco dependence was more than $50 \%$ in patients with 
psychotic disorders (73\%) and depression (60\%) while in other disorders harmful use was more common. In our study, out of 121 patients with depression $38 \%$ were found to be nicotine dependent.

In a study by Vanable P.A. et al $(2003)^{13}$ in Syracuse, New York in a sample from 2,906 consecutive outpatients at seven hospital-based outpatient psychiatric clinics, status to understand the elevated smoking rates among psychiatric patient, $61 \%$ of patients smoked daily, and that $18 \%$ smoked heavily (more than one pack per day). Patients with schizoaffective disorder reported the highest smoking rates $(67 \%)$, followed by patients with schizophrenia $(63 \%)$ and depression (60\%). Only 46.3\% $(n=56)$ patient with depression smoked tobacco in our study, so several variations in culture, income, distribution, and availability of tobacco product were probably revealed by this differences. As unlike the developed countries, in Nepal even for mentally ill persons there is a strong family system. So the family imposing restriction on smoking lowers rates of tobacco use. The ability to afford commercially-prepared tobacco products was limited by lower incomes for patient.

Milani et al (2012) ${ }^{14}$ studied to see pattern of smoking and nicotine dependence in patients with psychiatric disorders who had been hospitalized for at least 2 days in Razi Hospital, Iran by using FTND. Results showed out of total $70 \% \quad(78.4 \%$ of men and $36.2 \%$ of women) smokers, $64.4 \%$ had high nicotine dependence. Thus, smoking was related with advanced age, male sexuality, hookah consumption, and depression. In contrast to our study, the prevalence of high tobacco dependence was higher than that of our study $(n=46,38 \%)$. The difference may be due to the difference in cut-off point. Our study used a cut-off point of $>4$ FTND score. However, in that study used a $>3$ FTND score for high level of tobacco dependence

In another study of Heidi S. et al (2009) ${ }^{15}$, among $55 \%$ current cigarette smokers, $45.2 \%$ had Nicotine dependence (FTND 3 6) with the greatest prevalence in the substance use disorders and psychotic disorders groups. 51\% of patients were pre contemplative, $12.7 \%$ contemplative, and $36.2 \%$ preparatory or actionoriented, regarding readiness to quit, despite few receiving advices to quit. These finding are in accordance with our study that there was low level of motivation to quit smoking in those with depression $(n=69,57 \%)$. Among smokeless tobacco users, there was a negative correlation between nicotine dependence and readiness to quit in depression.

\section{CONCLUSION:}

Prevalence of nicotine use and dependence was found high among depression. Use of standardized and translated screening tools can be used efficiently to evaluate the burden of nicotine use in standard clinical practice in low resource setting like Nepal. Early screening for tobacco use disorder by use of simple screening tools such as FTND for smoked tobacco, Modified FTND for smokeless tobacco aids in the identification of problem and timely management hence these tools may be routinely used during diagnosis of psychiatric patients.

\section{Strength And Limitations:}

This study attempted to assess prevalence of nicotine use and dependence in depression. The study was conducted among both inpatient and outpatient subjects which made the sample more representative mixture of both severe and milder cases. It assessed the use and dependence of nicotine in term of both smoking and smokeless tobacco. Screening for nicotine use and dependence was done with the help of translated Nepali version of tools which was easy for the subjects to comprehend and answer. It was a cross-sectional study. The sample size of the study though adequate was still small in comparison to most of the cross-national study. The study relied on recall of smoking behavior; these answers may be impacted by recall bias especially within cross-sectional studies.

\section{ACKNOWLEDGEMENT:}

I am very grateful to our Head of Department, Prof. Dr. Saroj Prasad Ojha for his guidance and motivation throughout the entire residency period. I wish to express my sincere thanks and appreciation to Dr. Krishna Aryal, Chief of Research Section, Nepal Health Research Council who helped me by providing the Nepali version of the STEPS tools and finally I am very grateful to all the participants who participated 
in this research, without whom this would not have been possible.

\section{FUNDING: None}

\section{CONFLICT OF INTEREST: None}

\section{REFERENCES:}

1.Benowitz NL. Pharmacology of nicotine: addiction and therapeutics. Annual review of pharmacology and toxicology. 1996; 36: 597-613.

2. J D, N S, Z C, et al. The Tobacco Atlas. 6 ed. Atlanta: American Cancer Society, Inc., 2018.

3. Population MoHa. Ministry of Health and Population [Nepal] Non communicable diseases risk factors. 2014.

4. Lawrence D, Mitrou F and Zubrick SR. Smoking and mental illness: results from population surveys in Australia and the United States. BMC Public Health. 2009; 9: 285.

5. Dierker L and Donny E. The role of psychiatric disorders in the relationship between cigarette smoking and DSM-IV nicotine dependence among young adults. Nicotine $\mathcal{E}$ tobacco research : official journal of the Society for Research on Nicotine and Tobacco. 2008; 10: 439-46.

6. Prochaska JJ. Smoking and mental illness--breaking the link. The New England journal of medicine. 2011; 365: 196-8.

7. Compton MT, Daumit GL and Druss BG. Cigarette smoking and overweight/obesity among individuals with serious mental illnesses: a preventive perspective. Harvard review of psychiatry. 2006; 14: 212-22.

8. WHO and Health Mo. WHO-AIMS Report on Mental Health System in Nepal. 2006.

9. Heatherton TF, Kozlowski LT, Frecker RC and Fagerstrom KO. The Fagerstrom Test for Nicotine Dependence: a revision of the Fagerstrom Tolerance Questionnaire. British journal of addiction. 1991; 86: 1119-27.

10. Boyle RG, Jensen J, Hatsukami DK and Severson HH. Measuring dependence in smokeless tobacco users. Addict Behav. 1995; 20: 443-50.

11. Biener L and Abrams DB. The Contemplation Ladder: validation of a measure of readiness to consider smoking cessation. Health psychology : official journal of the Division of Health Psychology, American Psychological Association. 1991; 10: 360-5.

12. Aggarwal DN and Prakash DR. A cross sectional study of prevalence of tobacco use and its correlates in psychiatric in-patients

Int J Scientific Res. 7: 4-6.

13. Vanable PA, Carey MP, Carey KB and Maisto SA. Smoking among psychiatric outpatients: relationship to substance use, diagnosis, and illness severity. Psychology of addictive behaviors : journal of the Society of Psychologists in Addictive Behaviors. 2003; 17: 259-65.

14. Milani HS, Kharaghani R, Safa M, et al. Pattern of smoking and nicotine dependence in patients with psychiatric disorders. Tanaffos. 2012; 11: 55-60.
15. Solty $H$, Crockford $D$, White WD and Currie S. Cigarette smoking, nicotine dependence, and motivation for smoking cessation in psychiatric inpatients. Canadian journal of psychiatry Revue canadienne de psychiatrie. 2009; 54: 36-45. 